\title{
Emotion regulation, depression and self-harming behaviours in people with borderline personality disorder: the moderating role of action vs. state orientation
}

\author{
Sybilla Blasczyk-Schiep ${ }^{1 \cdot A, B, C, D, E, F, G}$, Paulina faworska-Andryszewska ${ }^{1,2 \cdot B, E}$, Ewelina Rabska ${ }^{1 \cdot B, E}$, \\ Agnieszka Lason ${ }^{1 \cdot B, E}$, Ewa Niezgoda ${ }^{3 \cdot A, B}$, Karolina Fila-Witecka ${ }^{1 \cdot A, E, F}$ \\ 1: SWPS University of Social Sciences and Humanities, Wroclaw, Poland \\ 2: Department of Psychiatry, Poznan University of Medical Sciences, Poznan, Poland \\ 3: Specialist Hospital Dr. J. Babinski, Krakow, Poland
}

\section{BACKGROUND}

The aim of this research is to determine the level of emotion regulation, studied through the method of variable action orientation vs. state and its relationship with depressiveness and dimension of the reasons for living and self-harming behaviour of patients with borderline personality disorder.

\section{PARTICIPANTS AND PROCEDURE}

The research studied 61 patients diagnosed with an emotionally unstable personality of borderline type. The research used the Polish adaptation of tests to measure the action vs. state orientation (SSI-K), the self-harming behaviour (SHI), depression (BDI) and the reasons for living vs. suicidal tendency (RFL-I).

\section{RESULTS}

In people with borderline personality disorder, the level of emotion regulation (action vs. state orientation), reasons for living and depression are predictors of self-harming behaviour. The experience of a depressive episode or lack thereof does not have a relationship with the increase of self-harming. Analysis of the interaction between variables showed that the reasons for living and the action orientation after failure are related to the reduction of self-harming behaviour in all subjects. In depressed people, state orientation is associated with an increase in the action orientation with decreased self-destructive behaviours.

\section{CONCLUSIONS}

High levels of reasons for living in interaction with the action orientation have a negative relationship with the self-harming behaviour of patients diagnosed with borderline personality disorder. Among those subjects, depressive patients, a statistically lower level of self-harm is related to the action orientation. These results suggest that therapeutic treatment is important to activate both reasons for living as well as action orientation as effective dimensions in preventing self-harming.

\section{KEY WORDS}

depression; self-harming; borderline personality; action vs. state orientation

CORRESPONDING AUthor - Sybilla Blasczyk-Schiep, Ph.D., SWPS University of Social Sciences and Humanities,

30 B Ostrowskiego Str., 53-238 Wrocław, Poland, e-mail: sblasczyk-schiep@swps.edu.pl

AUthors' CONtribution - A: Study design - B: Data collection · C: Statistical analysis - D: Data interpretation .

E: Manuscript preparation · F: Literature search · G: Funds collection

to Cite this ARticLE - Blasczyk-Schiep, S., Jaworska-Andryszewska, P., Rabska, E., Lason, A., Niezgoda, E.,

\& Fila-Witecka, K. (2016). Emotion regulation, depression and self-harming behaviours in people with borderline perso-

nality disorder: the moderating role of action vs. state orientation. Current Issues in Personality Psychology, 4(1), 41-49.

RECEIVED 19.08.2015 · REVIEWED 02.10.2015 · ACCEPTED 29.11.2015 · PUBLISHED 08.01.2016 


\section{BACKGROUND}

The inability to regulate emotions has been identified as the key core of borderline personality disorder (BPD), by many authors (Crowell, Beauchaine, \& Linehan, 2009). Borderline personality disorder is associated with decreased emotional awareness and perception as well as a poorer understanding of emotional states (Linehan, 1993a; Herr, Rosenthal, Geiger, \& Erikson, 2013; Meyer \& Morey, 2015). Emotional deregulation remains a predictor of borderline personality features, even when a person suffering from $\mathrm{BPD}$ is trying to manage their impulsiveness (Bradley, Conklin, \& Westen, 2006). People who meet the criteria of borderline personality disorder exhibit a biologically conditioned high sensitivity to negative emotions, combined with high emotional intensity and an elevated reactivity to emotionally evocative stimuli, as well as some issues to assert control over them (Linehan, 1993b).

\section{EMOTIONAL REGULATION IN THE ACTION CONTROL THEORY BY JULIUS KUHL}

The concept of emotional regulation is anchored in Julius Kuhl's Action Control theory (1994), which states that the competence of volitional affective self-regulation is associated with personality styles or an individual's sensitivity to affective states (extraversion, introversion and neuroticism), as well as action vs. state orientation, related to affective regulation (Kuhl \& Beckmann, 1994; Baumann, Kaschel, $\&$ Kuhl, 2007). Kuhl's theory (1994) postulates that it is not the affective sensitivity to positive or negative emotional states (i.e. the level of submersion in the emotional experience), but rather the regulation of these emotional states (i.e. how long they persevere) that is essential to the development of symptoms (Baumann et al., 2007). The type of orientation (state vs. action) exhibited by an individual directly affects their ability to self-regulate. While action orientation will benefit a person's self-regulatory abilities in terms of affective states, state-orientation will diminish them. According to Kuhl's theory, action orientation activates cognitive and emotional processes conducive to the implementation of activities, whereas state orientation blocks them. Kuhl defines emotional regulation as a person's ability to reduce the intensity of negative emotions (e.g. anxiety, hopelessness) or generate positive emotions in difficult and unpleasant circumstances (Kuhl \& Beckmann, 1994; Baumann et al., 2007). While the ability to reduce the intensity of negative emotions is related to action orientation after a failure, the capability of generating positive emotions is associated with action orientation in decision making situations, both of which have a significant impact on the overall emotional regulation. Emotional and cognitive detachment in the case of a failure are important because they result in a reduction in negative affect, while the ability to generate positive affect is essential since it promotes the motivation to act. Action orientation after a failure manifests in a rapid shift of focus from the bad experience to new challenges, thus reducing the unpleasant feelings associated with the negative experience. In the case of state orientation after a failure, that ability is greatly impaired and replaced by a tendency to excessively ruminate about defeat, which does not lead to a reduction of the experienced negative emotions.

Action orientation in decision-making situations is associated with the ability to generate positive emotions in order to promote taking action, even when difficulties arise. An action-oriented person can cope with a decrease in positive affect, associated with the difficulties emerging in the process of implementing their intention, and introduce a positive affect in order to facilitate the decision to act. A state-oriented person is unable to generate positive feelings that would motivate him or her to act (Kuhl \& Beckmann, 1994). With reference to these theoretical assumptions, it is important to address the question of whether action vs. state orientation, seen as an indicator of emotional regulation, is connected to the occurrence of self-harming behaviour in people with borderline personality disorder, and whether additional variables, such as the number of reasons for living or depressiveness, differentiate this relation.

\section{EMOTION REGULATION, DEPRESSION AND REASONS FOR LIVING IN PEOPLE WITH BORDERLINE PERSONALITY DISORDER}

Some researchers claim that people with BPD are biologically predisposed to experiencing depressive episodes (Millon, Grossman, Millon, Meagher, \& Ramnath, 2000). In Millon's et al. study (2000) $83 \%$ of the examined BPD patients reported at least one co-morbid depressive episode during their lifetime and $12 \%$ to $39 \%$ reported co-morbid dysthymia (Shea, Widiger, \& Klein, 1992; Zanarini et al., 1998; Zimmerman \& Mattia, 1999). Considering the components of borderline personality disorder, such as irritability, an increased level of negative emotions, low self-esteem, a sense of being worthless and a sense of lack of control, the occurrence of a depressive episode and/or a prolonged depressive state (i.e. dysthymia) does not seem an unlikely co-morbidity, and is in fact vastly supported by research (Lieb, Zanarini, Schmahl, Linehan, \& Bohus, 2004; Stone, 2006). However, the mechanisms and implications of the co-occurrence of BPD and depressive disorders have not yet been clearly established (Köhling, 2015). The fre- 
quency of personality disorders in people diagnosed with depression ranges from $23 \%$ to $87 \%$ (Millon et al., 2000). Undoubtedly, the feature most prominently shared by both disorders is the difficulty associated with experiencing strong negative emotions as well as various issues concerning their regulation.

The research on this topic shows a higher intensity of negative emotions among patients with borderline personality disorder, compared to members of a control group, patients with bipolar disorder and those with Axis II diagnoses (Levine, Marziali, \& Hood, 1997; Henry et al., 2001; Koenigsberg, Harvey, Mitropoulou, Schmeidler, \& New, 2002). The results suggest that the issue of emotional intensity and emotional deregulation is more severe in patients with borderline personality disorder than in other studied groups. Other research has shown a positive correlation between negative emotional intensity and features of borderline personality disorder (Cheavens et al., 2005) as well as the appearance of intense negative emotions during social interactions (Rosenthal, Cheavens, Lejuyez, \& Lynch, 2005; Russel, Moskowitz, Paris, Sookman, \& Zuroff, 2007; Herr et al., 2013). In their research Yen, Zlotnick and Costello (2002) define the relationship between the dimensions of affective regulation, depressiveness, and the features associated with borderline personality disorder in 38 women. The regression results showed that the level of intensity of affect and its control were significantly related to the amount of features of borderline personality disorder, even after taking into account the level of depression. Patients with BPD experience more intense emotions and have more difficulties controlling their emotional reactions.

Reisch, Ebner-Priemer, Tschacher, Bohus, and Linehan (2008) in their research rated the sequence of emotions (emotion temporal relationship) in order to determine the specific patterns of borderline personality disorder. Perceived emotions were studied in 50 patients with BPD and 50 unaffected controls using a hand-held computer system for 24 hours in everyday life situations. The participants rated their currently perceived emotions four times per hour. Individuals in the control group indicated joy and interest more frequently, while those with BPD often experienced persistence of fear and sadness. Individuals suffering from BPD, in this study, changed their emotions from fear to sadness, from fear to anger and from sadness to anxiety more frequently than the participants assigned to the control group, while anger was usually preceded by anxiety. The authors concluded that the durability of sadness and anxiety and the emotional oscillation between fear, sadness and anger are important aspects of the regulation of emotional problems in patients with borderline personality disorder (Reisch et al., 2008). In a study conducted by Bradley et al. (2006) clinicians examined randomly selected patients with BPD
( $n=90)$ and dysthymic disorder $(n=27)$ and found that patients with borderline personality disorder are different from patients with dysthymic disorder both in terms of emotions as well as in terms of their regulation. While patients with dysthymic disorder were characterised by negative affect, patients with borderline personality disorder not only exhibited negative affect, but also had trouble controlling it, which is the basis of this disorder. Patients suffering from borderline personality disorder also exhibit different patterns and profiles regarding affective regulation, which leads to the conclusion that the exploration of said constructs may be crucial for their treatment. Individuals with BPD tend to apply dysfunctional strategies to regulate their unpleasant emotional states, such as self-mutilation and self-harm. In an attempt to define a set of requisites related to self-destructive behaviour found in people diagnosed with borderline personality disorder, Holm and Severinsson (2010) analysed their origins. Women with BPD described their emotional pain as very intense, and to survive it they often turned to self-destructive behaviour. Thus, self-harm presents an opportunity for emotional relief, through the elimination of emotional pain by escaping unwanted feelings, thoughts or disturbing situations. In a longitudinal study Rietdijk, Bosch, Verheul, Koeter and Brink (2001) tried to establish whether self-harming and suicidal behaviour can be predicted based on the number of reasons for living, measured by the Reasons for Living Inventory (RFL-I, by Linehan, Goodstein, Nielsen, \& Chiles, 1983) questionnaire, during a 6-month period after the start of the study. The study examined the number of reasons for living, survival and coping beliefs, as well as the severity of depressive personality disorder traits in 38 patients with BPD. The study showed that people who had obtained a low score in "survival and coping beliefs" (which predicts suicidal and self-harming behaviour) were 6.8 times more likely to self-harm or display suicidal behaviour during the 6-month period than those who scored higher in this category. The strategies of coping in the Reasons For Living Inventory, especially the "faith in coping" subscale, turns out to be an important criterion for rating the risk of self-harming behaviour in patients with borderline personality disorder.

\section{AIMS AND HYPOTHESES}

The results of the research suggest that patients with borderline personality disorder demonstrate different patterns of affective regulation than, for example, patients suffering from depression, as well as different profiles of that regulation (Bradley et al., 2006), with a simultaneous tendency to use harmful strategies of emotional regulation, e.g. self-mutilation. Other researchers suggest that self-harming not only depends 
on the strategies of emotional regulation an individual applies, but also on the number of their reasons for living (Rietdijk et al., 2001). If we consider this information, the following questions may be asked: Which predictors are related to emotional regulation and self-harming as a consequence of deregulation of these emotions? Is the dimension of reasons for living, survival and coping beliefs and action vs. state orientation, as emotion regulation variables, a predictor of self-harming in patients with BPD? Do BPD patients with no depression, unlike those who suffer from it, show a different use of emotional control mechanisms (action vs. state orientation) associated with the reduction in the intensity of self-harming behaviour? Based on theoretical considerations we propose the following hypotheses:

- $\mathrm{H}_{1}$ - emotional regulation factors (state vs. action orientation) and depression, as well as survival and coping beliefs and the level of reasons for living, are predictors of self-harming behaviour in patients with borderline personality disorder,

- $\mathrm{H}_{2}$ - there is an association between self-regulation (state vs. action orientation) and the level of reasons for living (i.e. survival and coping beliefs) and self-harming behaviour. These associations are different for non-depressed and depressed patients with BPD.

\section{PARTICIPANTS AND PROCEDURE}

\section{PARTICIPANTS}

The study consisted of 61 patients diagnosed with borderline personality disorder $(n=61)$. The research was conducted in inpatient health care facilities in Poland (Krakow, Wroclaw and Poznan). The group consisted of 45 women (78\%) and 16 men (22\%) aged between 19 and 43 years old $(M=27.49, S D=6.43$ vs. $M=27.68, S D=6.31)$. The patients were diagnosed with an Emotionally unstable personality disorder, borderline type (F 60.31), based on the ICD-10 criteria, and were hospitalized in psychiatric institutions for treatment.

Forty-six patients (78\%) were also diagnosed with a co-morbid disorder. The most frequent co-occurring disorder was depression (diagnosed in 22 patients), for 20 patients the second diagnosis was that of an anxiety disorder, adjustment disorders in 9 patients, eating disorders in 19 patients and in 17 patients it was psychoactive substance dependence.

\section{MEASURES}

Standardised questionnaires were used to verify the hypotheses. In order to measure self-destructive behaviour, the Self-Harm Inventory was applied (SHI;
Sansone, Wiederman, \& Sansone, 1998) (translated into Polish for the study, with the permission of the author). Overall test scores, defined as the sum of "yes" answers, range from 0 to 22 points, and a result of 5 or higher suggests a tendency for self-destructive behaviour and borderline personality disorder. The overall reliability of the test is high for the Polish version and equals $\alpha=.83$.

Reasons for Living were examined using the RFL-I (Linehan et al., 1983), with the permission of the author to translate it into Polish (Blasczyk-Schiep, 2004). The Reasons For Living Inventory is theoretically based, and measures the probability of suicide based on the theory that some factors may mitigate suicidal thoughts. RFL-I is an inventory which allows one to establish what reasons to keep on living the patient perceives, and which consequences of suicide he or she sees. Negative (low) results indicate suicidal behaviour. The questionnaire has 6 scales: Survival and coping beliefs, Responsibility for the family, Fears about children, Fear of suicide, Fear of social disapproval, and Moral objection. The reliability of the scale lies between .73 and .87 .

The Action orientation vs. State orientation variables were measured using the corresponding scale of the Volitional Components Inventory (VCI; Kuhl \& Fuhrmann, 1998), in the Polish translation (with permission of the author) by Blasczyk-Schiep (2004). The Action orientation vs. State orientation in the Decision-Making Situations (Prospective) scale examines the reactivation of positive affect following its inhibition (e.g. a sense of sadness, frustration) in a difficult or aggravating situation. Positive affect is required to activate the process of starting an action. The Action orientation vs. State after the failure scale evaluates the dimensions of negative affect regulation in a difficult or threatening situation, in which the current living conditions worsen, negative emotional states and coping in stressful situations (e.g. anxiety or emotional tension reduction). The reliability of the aforementioned scales is .80 and .82 , respectively.

The level of depression and/or the presence of a current depressive episode was measured with the Beck Depression Inventory (BAI; Beck \& Steer, 1990). It is a standardized inventory created by Aaron Beck (1990) used in diagnosing depression, which allows the patient to self-assess the presence and severity of symptoms. The more points a patient gets in 21 blocks of the BDI, the more likely they are to experience a depressive episode.

\section{RESULTS}

In order to verify the first hypothesis and examine predictors for self-harming behaviour, a correlation analysis was performed (Table 1). 
Sybilla Blasczyk-Schiep, Paulina Jaworska-Andryszewska, Ewelina Rabska, Agnieszka Lason, Ewa Niezgoda, Karolina Fila-Witecka

Table 1

Matrix of correlation between variables $(n=61)$

\begin{tabular}{lcccc}
\hline Scale & SHI & AOD $/$ SOD & AOF/SOF & BDI \\
\hline SHI & 1.000 & $0.404^{*}$ & $0.404^{*}$ & $0.634^{* *}$ \\
RFL-A & $-0.552^{* *}$ & $-0.512^{* *}$ & $-0.401^{*}$ & $-0.635^{* *}$ \\
RFL-1 & $-0.553^{* *}$ & $-0.546^{* *}$ & $-0.456^{* *}$ & $-0.630^{* *}$ \\
RFL-2 & $-0.356^{*}$ & $-0.390^{*}$ & $-0.308^{*}$ & $-0.374^{*}$ \\
RFL-3 & $-0.421^{*}$ & $0.452^{*}$ & 0.215 & $-0.336^{*}$ \\
RFL-4 & -0.056 & 0.079 & 0.101 & $-0.312^{*}$ \\
RFL-5 & 0.013 & 0.040 & -0.044 & -0.016 \\
RFL-6 & -0.115 & -0.094 & -0.052 & -0.024 \\
\hline
\end{tabular}

Note. ${ }^{* * *} p<.001,{ }^{* *} p<.01,{ }^{*} p<.05$; SHI - Self-Harm Inventory, RFL-I Overall Score, RFL-1 - Survival and coping beliefs, RFL-2

- Responsibility for the family, RFL-3 - Fears about children, RFL-4 - Fear of suicide, RFL-5 - Fear of social disapproval, RFL-6

- Moral objection, AOD/SOD - Action orientation vs. State orientation Prospective, AOF/SOF - Action orientation vs. State

orientation after the failure, BDI - Beck Depression Inventory

On the basis of Table 1 an analysis of linear regression was conducted, by introducing each of the predictor variables into a separate regression equation. The regression analysis showed that the predictor, which is the overall level of reason for living (overall score RFL-I), is related to the level of self-harming behaviour. This predictor explains about $39 \%$ of the variability $\left(R^{2}=.39\right)$ of self-harming behaviour (Table 2$)$.

It has also been shown that there is a strong, significant relationship between the predictors of responsibility for the family and fears about children; these predictors explained $41 \%, 21 \%$ and $17 \%$ of the variability of self-harming behaviour, respectively. A strong relationship between the depression predictor and self-harming behaviour is also apparent - this predictor explains $38 \%$ of the variability of this behaviour. Also there is a relationship between state orientation after a failure and state orientation in the situation of making a decision and self-harming behaviour. These predictors explain $13 \%$ and $9 \%$ of the variability of the self-harming behaviour, respectively.

The analysis revealed no relationship between the variables of fear of suicide, fear of social disapproval and moral objection and self-harming behaviours.

In order to verify the second hypothesis, as a first step the relationship between emotional regulation

Table 2

Relationship between tested variables and self-destructive behaviour measured with SHI inventory, as a dependent variable, the table of linear regression

\begin{tabular}{lcccc}
\hline Scale & $F(d f)$ & $\mathrm{B}$ & $\beta$ & $R^{2}$ \\
\hline RFL-A & $39.63(1.63)$ & -.06 & $-.62^{* * *}$ & .39 \\
RFL-1 & $42.86(1.63)$ & -.09 & $-.64^{* * *}$ & .41 \\
RFL-2 & $16.56(1.63)$ & -.19 & $-.46^{* *}$ & .21 \\
RFL-3 & $12.35(1.63)$ & -.32 & $-.41^{* *}$ & .17 \\
RFL-4 & $2.32(1.63)$ & -.11 & -.19 & .04 \\
RFL-5 & $0.52(1.63)$ & .84 & -.09 & .01 \\
RFL-6 & $0.93(1.63)$ & -.86 & -.12 & .02 \\
no MD vs. MD & $0.68(1.43)$ & -.83 & -.12 & .02 \\
BDI & $38.55(1.63)$ & .19 & $.62^{* *}$ & .38 \\
AOF/SOF & $8.84(1.63)$ & .48 & $.35^{*}$ & .13 \\
AOD/SOD & $6.44(1.63)$ & .42 & $.31^{*}$ & .09 \\
\hline
\end{tabular}

Note. ${ }^{* *} p<.001,{ }^{* *} p<.01{ }^{*} p<.05$; SHI - Self-Harm Inventory, RFL-I Overall Score, RFL-1 - Coping beliefs, RFL-2 - Responsibility for the family, RFL-3 - Fears about children, RFL-4 - Fear of suicide, RFL-5 - Fear of social disapproval, RFL-6 - Moral principles, no MD vs. MD no presence of Major Depression episode or presence, BDI - Beck Depression Inventory, AOD/SOD - Action orientation vs. State orientation Prospective, AOF/SOF - Action orientation vs. State orientation after the failure 
and action vs. state orientation and the reasons for living dimensions (i.e. the meaning of life) were tested with the RFL-I and self-harming behaviours (in $\mathrm{SHI}$ ) as dependent variables. The following variables were included as predictors, in the first regression: Reasons for Living (total score) and affect regulation scale (action vs. state orientation) in step 1, and their interaction in step 2. A hierarchical regression analysis of interaction (Cohen, Cohen, West, \& Aiken, 2003) was applied (coded regression lines 1 SD above and 1 SD below the mean value of the moderator).

In the hierarchical regression, for the dependent variable self-harming behaviour, the variables reasons for living and failure-related action vs. state orientation were entered at the first step and accounted for $34 \%$ of the variability $\left(R^{2}\right)$. The model was statistically significant, $F(2,59)=15.46, p<.001$.

The standardized beta coefficients of the model at Step 1 were, as follows: reasons for living $\beta=-.60$ $(t=-.59, p<.001)$, failure-related action vs. state orientation, $\beta=.12(t=1.26$, n.s.). To verify hypothesis 2 the inclusion of the predictors' interaction at Step 2 yielded a significant model, $F(3,58)=15.97, p<.001$, and $4 \%$ of the variance ( $R^{2}$ change: $\left.p<.05\right)$. The standardized beta coefficients of the final model at Step 2 were as follows: reasons for living $\beta=-.58$ $(t=-5.54, p<.001)$, failure-related action vs. state orientation, $\beta=-.57(t=-1.63$, n.s. $)$ and reasons for living $\times$ failure-related action vs. state orientation, $\beta=.21$ $(t=2.01, p<.05)$. The results are shown in Figure 1. People with a low level of reasons for living demonstrate a higher correlation with self-harming behaviours than those who express a high level of reasons for living. People who are action oriented with a high level of reasons for living demonstrate a more negative relationship in relation to self-harming and thus are less self-harming than people with low lev-

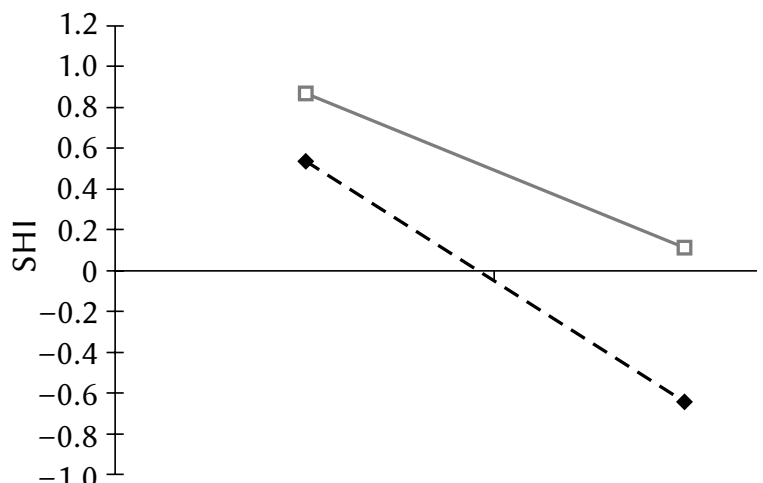

Low RFL

High RFL

- - AOF $\quad-\square-$ SOF

Figure 1. Self-harming behaviour (SHI, mean standardised score) as a function of the level of reasons for living (low RFL - low level of reasons for living; high RFL - high level of reasons for living) and affective regulation (failure-related action vs. state orientation, AOF vs. SOF). els of reasons for living, who are state oriented. Further analyses of the hierarchical regression, related to action vs. state orientation in decision making situations, RFL and subscales of the reasons for living questionnaire as predictors of self-harm behaviour yielded no significant results.

At the end we divided the subjects into two groups: one consisting of patients currently diagnosed with a depressive episode $(n=22)$ and the second not diagnosed with a depressive episode $(n=22$, excluding substance dependence). We studied the relationships between the groups (depressed persons vs. non-depressed persons) and action vs. state orientation after failure (AOF vs. SOF) in relation to the dependent variable which was self-harming behaviours. AOF and SOF variables (action orientation vs. state orientation after a failure) and group (depressed vs non-depressed) in the first step occurred in $10 \%$ of cases of variation $\left(R^{2}\right)$, and the model was statistically significant, $F(2,42)=2.70, p<.05$. Standardized $\beta$ coefficients of the model in Step 1 were as follows: Group $\beta=.04(t=0.03$, n.s. $)$, SOF $\beta=.32(t=2.23$, $p<.05)$. To verify hypothesis 2 the inclusion of interaction predictors in Step 2 resulted in a more significant model, $F(2,41)=3.61, p<.02$, and an additional $11 \%$ of the variance $\left(R^{2}\right.$ change: $\left.p<.02\right)$. $\beta$ coefficients of the final model in Step 2 were as follows: Group $\beta=.05(t=0.35$, n.s. $)$, SOF, $\beta=.05(t=0.27$, n.s. $)$ and SOF $\times$ Group, $\beta=.43(t=2.35, p<.05)$.

A negative relationship with self-harm and thus less self-harming behaviours was found in those subjects with depression who were action oriented, whereas a positive one was found in those who were state oriented. This relationship was statistically significant compared to all other groups. There were no significant effects for non-depressed subjects. Further hierarchical regression analyses with decision-relat-

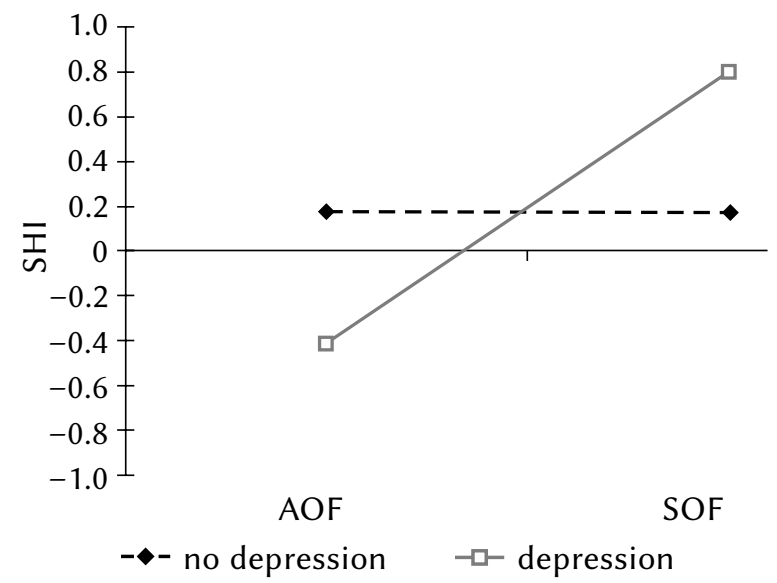

Figure 2. Self-harming behaviour (SHI, mean standardised score) as a function of affective regulation (AOF - action orientation, SOF - state orientation after the failure) and depression. 
ed action vs. state orientation (AOD vs. SOD) and group (depressed vs. non depressed), and reasons for living and group as predictors of self-harm behaviour likewise yielded no significant results.

\section{DISCUSSION}

In our study we found statistically significant predictors of self-harming behaviour in patients with borderline personality disorder. The results suggest that state orientation associated with low emotional regulation coupled with fewer reasons for living as well as survival and coping beliefs exacerbate the level of self-harming behaviours in individuals afflicted with borderline personality disorder. There was no statistically significant correlation between self-harm and depressive episodes, except for the general amount of depressive features (as measured by the BDI score). Similarly, the research conducted by Yen et al. (2002) also demonstrated that affect intensity and an individual's control over it were significantly related to the extent of borderline personality disorder symptoms displayed, even after taking into account the level of depression.

The results suggest that people with BPD display fewer self-harm behaviours when action oriented (i.e. with a greater ability to regulate their emotional states) than state oriented, especially while simultaneously displaying higher levels of reasons for living, in relation to other people (Figure 1).

Among the patients suffering from depression who have also been diagnosed with BPD, the action-oriented individuals exhibit less self-harming behaviours than their state-oriented and non-depressive counterparts (Figure 2).

The aforementioned tests also confirm the results obtained by Bradley et al. (2006), stating that people with BPD experience a larger amount of negative emotions which they perceive as hard to control. Patients suffering from BPD exhibit different patterns of affective regulation, and determining which of those patterns is applied by the patient may be an important factor in the treatment and prevention of maladaptive strategies of emotional regulation (i.e. self-mutilation in response to experiencing unpleasant emotions). The role of action orientation in affective regulation in people with BPD has also been empirically confirmed by other studies. Baumann's studies (2007) demonstrated that people characterised by a borderline personality style experienced fewer psychosomatic symptoms if they were action oriented. In other studies (Kuhl, 2001) action orientation was found to exhibit a negative correlation in relation to self-harm and suicidal tendencies in people with BPD. The Action vs. State orientation after a Failure scale evaluates the dimension of negative affect regulation in difficult or threatening situations, when negative emotional states and coping in stressful situations increase (anxiety or tension reduction). After experiencing a failure, action oriented individuals quickly recover and are able to regulate their negative emotions, such as anxiety, and start to take on new activities soon. State oriented people with BPD tend to ruminate about their unpleasant experience after a failure, which inhibits their activity whilst intensified anxiety or emotional tension increases their self-harm tendencies. This scenario reflects the results of BPD studies, where state orientation was related to a certain amount of difficulty in regulating negative emotions, promoting the occurrence of selfharm in situations characterized by high emotional tension. These results are mirrored in other studies as well, where the authors postulate that the persisting feelings of sadness and anxiety, as well as oscillating between fear, sadness and anger, are important aspects in regard to the issues concerning emotional regulation displayed by patients suffering from BPD (Reisch et al., 2008). The aforementioned results justify the conclusion that coping mechanisms and negative emotionality, or action orientation after a failure, are important factors related to the concept of emotional regulation in BPD sufferers. The activation of positive affect in difficult situations, or action orientation in decision making situations, is of less importance when it comes to emotional regulation. When considering self-harm displayed by BPD patients, action orientation in decision making situations has not proven to be an important dimension of affective regulation. People with borderline personality disorder who are action-oriented have the ability to calm themselves down and relive negative emotions after a failure in a situation of emotional tension or anxiety, which may act as a protective factor in relation to self-harming behaviour. Strengthening this ability [e.g. by introducing the so-called applied skills in the course of dialectical-behavioural therapy - DBT (Linehan, 1993a)], can therefore prove to be effective in the regulation of emotions for people with BPD.

Studies have shown that the number of reasons for living, particularly survival and coping beliefs activated in difficult situations, are related to a reduction in self-harming behaviours in all patients suffering from BPD (depressive and non-depressive, alike), especially in an interaction with action orientation (Citation). Another study by Rietdijk et al. (2001) confirms that the coping strategies included in the Reasons For Living Inventory, especially in the subscale "survival and coping beliefs" (related to coping strategies, such as comforting thoughts, activating coping and patterns of sedative reaction), turn out to be an important criterion for evaluating the risk of self-harming behaviour in people with BPD. According to the researchers, high scores on this scale predict less self-harm in the period following the measurement (Rietdijk et al., 2001). 
Our findings regarding the moderating role of action vs. state orientation in the context of self-harming behaviours in people diagnosed with BPD represent a new approach. In relation to the existing empirical data, where these dimensions have already been well verified in personality psychology (Baumann et al., 2007; Kuhl, 2001; Kuhl \& Fuhrmann, 1998), it is very important to now confirm their relevance and validity in clinical trials. This study also has limitations, such as the following: a lack of homogeneity in the tested groups, due to a high frequency of co-morbid psychopathology occurring in patients with BPD (high depressiveness, anxiety, addiction, etc.) and no gender-based comparisons as a result of a predominantly female sample. The results, however, have implications for therapy and further studies. Dialectical behaviour therapy has been documented as one of the most effective approaches in the treatment of borderline personality disorder (Lieb et al., 2004; Koons et al., 2001; Linehan, Armstrong, Suarez, Allmon, \& Heard, 1991; van den Bosch, Koeter, Stijnen, Verheul, \& van den Brink, 2005), possibly due to its focus on emotion regulation and the acceptance of emotional distress (Kliem, Kröger, \& Kofelder, 2010). However, the effectiveness of therapeutic techniques concerning emotional regulation and the development of an action orientation and a higher amount of reasons for living as well as the part they play in the process of healing require further longitudinal studies. To investigate these effects it is important to examine the aforementioned variables in a randomised trial conducted during the therapy process for people with borderline personality disorder.

\section{References}

Baumann, N., Kaschel, R., \& Kuhl J. (2007): Affect sensitivity and affect regulation in dealing with positive and negative affect. Journal of Research in Personality, 41, 239-248.

Beck, A. T., \& Steer, R. A. (1990). Manual for the Beck Anxiety Inventory. San Antonio, TX: Psychological Corporation.

Blasczyk-Schiep, S. (2004). Selbssteuerung und Suizidrisiko [Self-regulation and suicidal risk]. Bern, New York: Peter Lang.

Bradley, R., Conklin, C., \& Westen, D. (2006). Affect regulation in Borderline Personality Disorder. Journal of Nervous \& Mental Disease, 194, 69-77.

Cohen, J., Cohen, P., West, S., \& Aiken, L. (2003). Applied multiple regression / correlation analysis for the behavioural sciences ( $3^{\text {th }}$ ed.). New York: Erlbaum.

Crowell, S. E., Beauchaine, T. P., \& Linehan, M. M. (2009). A biosocial developmental model of borderline personality: elaborating and extending Linehan's theory. Psychological Bulletin, 135, 495-510.
Cheavens, J. S., Rosenthal, M. Z., Daughters, S. D., Novak, J., Kossen, D., Lynch, T. R., \& Lejuez, C. W. (2005): An analogue investigation of the relationships among perceived parental criticism, negative affect, and borderline personality disorder features: the role of thought suppression. Behaviour Research and Therapy, 43, 257-268.

Henry, C., Mitropoulou, V., New, A. S., Koenigsberg, H. W., Silverman, J., \& Siever, L. J. (2001): Affective instability and impulsivity in borderline personality and bipolar II disorders: Similarities and differences. Journal of Psychiatry Research, 35, 307-312.

Herr, M. R., Rosenthal, N. Z., Geiger, P. J., \& Erikson, K. (2013). Difficulties with emotion regulation mediate the relationship between borderline personality disorder symptom severity and interpersonal problems. Personality and Mental Health, 7, 191202. DOI: $10.1002 / p m h .1204$

Holm, A. L., \& Severinsson, E. (2010). Desire to survive emotional pain related to self-harm: a Norwegian hermeneutic study. Nursing Health Sciences, $12,52-57$.

Kliem, S., Kröger, C., \& Kosfelder, J. (2010). Dialectical Behavior Therapy for Borderline Personality Disorder: A meta-analysis using mixed-effects modeling. Journal of Consulting and Clinical Psychology, 78, 936-951.

Koenigsberg, H. W., Harvey, P. D., Mitropoulou, V., Schmeidler, J., \& New, A. S. (2002). Characterizing affective instability in borderline personality disorder. American Journal of Psychiatry, 159, 784-788.

Koons, C. R., Robins, C. J., Tweed, J. L., Lynch, T. R., Gonzales, A. M., Morse, J. Q., \& Bastian, L. A. (2001). Efficacy of dialectical behavior therapy in women veterans with borderline personality disorder. Behavior Therapy, 32, 371-390.

Köhling, J. (2015). Quality and severity of depression in borderline personality disorder: A systematic review and meta-analysis. Clinical Psychology Review, 37, 13-25.

Kuhl, J., \& Fuhrmann, A. (1998). Decomposing Self-Regulation and Self-Control: The Volitional Competencies Inventory. In: J. Heckhausen, \& C. S. Dweck (eds.), Motivation and Self-Regulation Across the Life Spean (pp. 15-49). Cambridge: Cambridge University Press.

Kuhl, J. (2001). Motivation und Persönlichkeit [Motivation and personality]. Göttingen: Hogrefe.

Kuhl, J., \& Beckmann, J. (1994). Volition and Personality: Action vs. state orientation. Göttingen: Hogrefe.

Levine, D., Marziali, E., \& Hood, J. (1997). Emotion processing in borderline personality disorders. Journal of Nervous Mental Disorder, 185, 240-246.

Lieb, K., Zanarini, M. C., Schmahl, C., Linehan, M. M., \& Bohus, M. (2004). Borderline personality disorder. Lancet, 364, 453-461. 
Linehan, M. M. (1993a). Skills training manual for treating borderline personality disorder. New York, NY: Guilford Press.

Linehan, M. M. (1993b). Cognitive behavioral treatment of borderline personality disorder. New York: Guilford Press.

Linehan, M. M., Armstrong, H. E., Suarez, A., Allmon, D., \& Heard, H. L. (1991). Cognitive-behavioral treatment of chronically parasuicidal borderline patients. Archives of General Psychiatry, 48, 1060-1064.

Linehan, M. M., Goodstein, J. L., Nielsen, S. L., \& Chiles, J. A. (1983). Reasons for staying alive when you are thinking of killing yourself: The Reasons for Living Inventory. Journal of Consulting and Clinical Psychology, 51, 276-286.

Meyer, J., \& Morey, L. (2015). Borderline personality features and associated difficulty in emotion perception: An examination of accuracy and bias. Personality and Mental Health, 9, 227-240.

Millon, T., Grossman, S., Millon, C. M., Meagher, S., \& Ramnath, R. (2000). Personality disorders in modern life $\left(2^{\text {th }}\right.$ ed.). New Jersey: Wiley.

Reisch,T., Ebner-Priemer, U., Tschacher,W., Bohus, M., \& Linehan, M. M. (2008). Sequences of emotions in patients with borderline personality disorder. Acta Psychiatrica Scandindinavia, 118, 42-48.

Rietdijk, E., Van den Bosch, L., Verheul, R., Koeter, M., \& Van den Brink, W. (2001). Predicting self-damaging and suicidal behaviors in female Borderline patients: Reasons for living, coping, and Depressive Personality Disorder. Journal of Personality Disorders, 15, 512-520.

Rosenthal, M. Z., Cheavens, J. S., Lejuyez, C. W., \& Lynch, T. R. (2005). Thought suppression mediates the relationship between negative affect and borderline personality disorder symptoms. Behavioral Research and Therapy, 43, 1173-1185.

Russell, J. J., Moskowitz, D. S., Paris, J., Sookman, D., \& Zuroff, D. C. (2007). Stability and variability of affective experience and interpersonal behavior in Borderline Personality Disorder. Journal of Abnormal Psychology, 116, 578-588.

Sansone, R. A., Wiederman, M. W., \& Sansone, L. A. (1998). The Self-Harm Inventory (SHI): Development of a scale for identifying self-destructive behavior and borderline personality disorder. Journal of Clinical Psychology, 54, 973-983.

Shea, M. T., Widiger, T. A., \& Klein, M. H. (1992). Comorbidity of personality disorders and depression: Implications for treatment. Journal of Consulting and Clinical Psychology, 60, 857-868.

Stone, M. H. (2006). Management of borderline personality disorder: a review of psychotherapeutic approaches. World Psychiatry, 5, 15-20.

van den Bosch, L. M. C., Koeter, M. W. J., Stijnen, T., Verheul, R., \& van den Brink, W. (2005). Sustained efficacy of dialectical behaviour therapy for bor- derline personality disorder. Behaviour Research and Therapy, 43, 1231-1241.

Yen, S., Zlotnick, C., \& Costello, E. (2002). Affect regulation in women with borderline personality disorder traits. Journal of Nervous and Mental Disease, 190, 693-696.

Zanarini, M. C., Frankenburg, F. R., Dubo, E. D, Sickel, A. E., Trikha, A., Levin, A., \& Reynolds, V. (1998). Axis I comorbidity of borderline personality disorder. American Journal of Psychiatry, 155, 1733-1739.

Zimmerman, M., \& Mattia, J. I. (1999). Differences between clinical and research practice in diagnosing borderline personality disorder. American Journal of Psychiatry, 156, 1570-1574. 